\title{
Sounding Rocket Booster Design, Manufacture and Testing
}

\author{
Minh Hoang Do, Chin E. Lin, and Yei Chin Chao
}

\begin{abstract}
The Unmanned Aerial Vehicles (UAVs) are widely applied in daily life with different purposes recently. This UAV was designed to fulfill a specific mission: launch a sounding rocket at high altitude. The specifications of the UAV are 3.2 meters wingspan, maximum take-off weight (MTOW) is $25(\mathrm{~kg})$ (10 $(\mathrm{kg})$ payload included), service ceiling is 800 meter and operating range is $\mathbf{2} \mathbf{~ k m}$. Computational Fluid Dynamics (CFD) software (XLFR5, CFX5) is used for design process. UAV structure are made from foam, fiber glass and epoxy glue instead of balsa wood as traditional method. This thesis proposes a procedure to build the UAV from initial ideas to preliminary designs, CAD designs, then manufacture and lastly flight test and verification.
\end{abstract}

Index Terms - Unmanned aerial vehicle, rock booster, CFD analysis, CAD, manufacture.

\section{INTRODUCTION}

In astronautic study, sounding rocket is used to carry instruments or sensors for atmosphere physics data acquisition at high altitude. As a small size, the sounding rocket consumes more than half of its fuel in the initial phase of take-off. To improve its launch efficiency, mid-air launch concept from a flying carrier was proposed by scientists. Based on the application of UAV, a special design UAV can be used as a carrier to launch the $10(\mathrm{~kg})$ sounding rocket.

This thesis proposes a fixed wing UAV design with specific mission requirements as a sounding rocket booster by developing a useful methodology for airplane design. Foam, fiber glass and epoxy glue are used for manufacturing the wing, instead of balsa wood as traditional method.

\section{UAV DESIGN METHOD}

UAV design is a complicated and challenge work that needs to consider from an array of many aspects and its effects to the final result, such as: aerodynamics, propulsion, control, structure, a trade-off among those factors. This makes the UAV not only in good performance but also cost affordable in development project.

By combining both hi-end (ANSYS - CFX) and mid-end (XLFR5) computational analysis software to estimate the aerodynamic and stability performance of this design instead of using wind tunnel - a traditional method, a lot of time and

Manuscript received July 21, 2018; revised September 6, 2018.

Minh Hoang Do is with National Cheng Kung University, Tainan, Taiwan (e-mail: minhhoangdo0913@gmail.com). money for the design process are saved. Although it takes more time to run the computational analysis in comparison with wind tunnel tests. The design process is more prompt by considering the situation of analyzing more cases in a short time by using computational analysis software. The general requirements of the proposed UAV are cruise speed is 90 $(\mathrm{km} / \mathrm{h})$, carrying a rocket that weights $10(\mathrm{~kg})$, service ceiling is $800(\mathrm{~m})$, flying range is $2(\mathrm{~km})$, maximum take-off weight (MTOW) is $25(\mathrm{~kg})$. Each flight, UAV carries a rocket, so the best location is below and along the fuselage. In the very first step, it is important to translate correctly the demands of the mission to the design requirements.

TABLE I: FROM MISSION DEMAND TO DESIGN REQUIREMENTS
\begin{tabular}{|l|l|}
\hline $\begin{array}{l}\text { Mission } \\
\text { requirements }\end{array}$ & Design Requirements \\
\hline $\begin{array}{l}\text { High Payload } \\
\text { Capacity }\end{array}$ & $\begin{array}{l}\text { High Thrust + High lift devices } \\
\text { Low Stall Velocity }\end{array}$ \\
\hline High Airspeed & $\begin{array}{l}\text { Minimize parasite and induced drag } \\
\text { Sufficient thrust at high airspeed }\end{array}$ \\
\hline Stable Flight & $\begin{array}{l}\text { Achieve static and dynamics stability. } \\
\text { Structure stiffer }\end{array}$ \\
\hline
\end{tabular}

\section{A. Booster Operating Principle}

A rocket booster flight has 5 main phases which are shown in the Fig. 1.

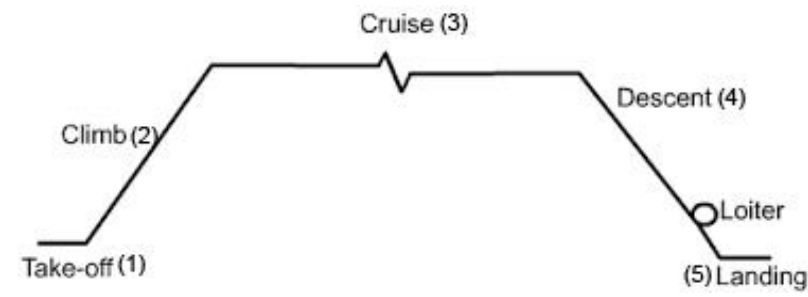

Fig. 1. Rocket booster flight phases.

Each phase has specific conFig.s for flight control and power distribution. Phase 1 is really short and in phase 2 , booster's characteristics in stability (weight, trim angle, thrust) change quite small. Therefore, phase 1 and 2 are combined to phase $\mathrm{A}$ in power distribution. Booster in phase 3 is described in the Fig. 2.

Before the launch, a booster cruises with rocket-attached configurations (elevator trim angle, throttle, CG position). Two motors are set to $100 \%$ to reach the desire speed for launching the rocket. After launching, the change in airplane weight is really huge (10 (kg) - 40\% of the MTOW) and CG is slightly moving backward, which leads to a pitch up moment. Therefore, at the time very close to the launching time, two motors are shut down to reduce the pitch up 
moment due to the decrement lift. At right after the ignition point, the rocket booster flips over with the same direction as the pitch up moment, then it returns to the equilibrium state. Rocket-released configurations are applied to the booster. It is estimated to take about 20 seconds to fulfill phase 3 , so the power distributed for phase 3 is about three times ( 70 seconds) as estimated in case the first attempt is not successful.

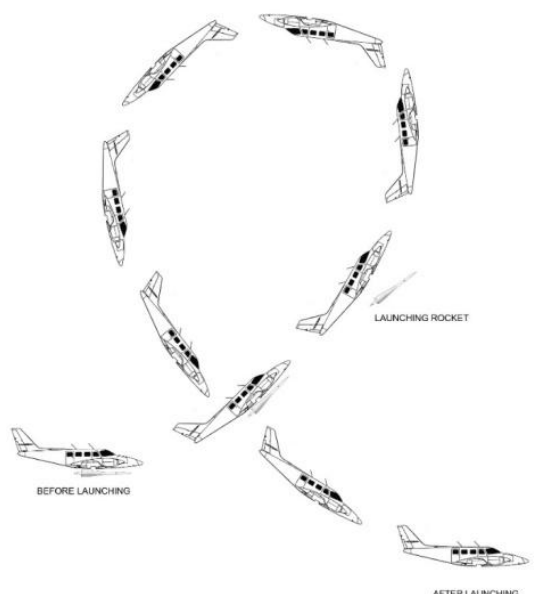

Fig. 2. Rocket booster in phase 3 .

After launching the rocket, the airplane weight has been reduced to $15(\mathrm{~kg})$. A rocket booster is designed to descend in gliding mode and landing at $40 \%$ throttle (4 kg thrust). Therefore, phase $\mathrm{C}$ only consumes $10 \%$ of the power, which means more power could be used in phase A, B. Phase 4 and 5 have same configurations and most of the power is used in phase 4 so it could be combined into phase $\mathrm{C}$ in power distribution table.

Propulsion system is supplied by a set of 10 cells battery (42 V $-5200 \mathrm{mAh})$. Only $90 \%$ of the battery $(4,680 \mathrm{mAh})$ is allowed to be used up. According to the performance of the booster in each phase and motor performance experiment data (Motor: Turnigy G160, Propeller $16 \times 10-2$ blades, 10 cells $-42 \mathrm{~V}$ battery), power distribution is summarized and shown in Table II below:

TABLE II: POWER DISTRIBUTION FOR DIFFERENT PHASES OF ROCKET

\begin{tabular}{|l|l|l|l|l|l|}
\hline \multirow{2}{*}{ Phase } & & & $\begin{array}{l}\text { A } \\
(1,2)\end{array}$ & $\begin{array}{l}\text { B } \\
(3)\end{array}$ & $\begin{array}{l}\text { C } \\
(4,5)\end{array}$ \\
\hline Proportion & $(\%)$ & 100 & 40 & 50 & 10 \\
\hline Power & $(\mathrm{mAh})$ & 4,680 & 1,872 & 2,340 & 468 \\
\hline Thrust & $(\mathrm{kg})$ & & 14 & 16 & 4 \\
\hline Throttle & $(\%)$ & & 80 & 100 & 40 \\
\hline Current & $(\mathrm{A})$ & & 70 & 120 & 16 \\
\hline Endurance & $(\mathrm{s})$ & 272 & 96 & 70 & 105 \\
\hline
\end{tabular}

\section{B. Wing Design}

From real flight data adapted from [2], [3] and also from wing structure limits, a NACA 6415 airfoil is chosen. Carbon tubes are used as main and rear spar of the wing. Compromise among the diameters, placement of carbon tubes with the structure goals, aerodynamic efficiency, UAV weight, etc., the mean chord of the wing of $0.45 \mathrm{~m}$ is chosen. Finally, the main specifications of the wing are shown in the Table III below:

TABLE III: WING SPECIFICATIONS

\begin{tabular}{|l|c|}
\hline Specifications & Value \\
\hline Wing area $\left(\mathrm{m}^{2}\right)$ & 1.44 \\
\hline Airfoil & NACA 6415 \\
\hline Wing chord (meter) & 0.45 \\
\hline Wing span (meter) & 3.2 \\
\hline Aspect ratio & 7.11 \\
\hline Tapper ratio & 1 \\
\hline
\end{tabular}

Purpose of wing structure test is to measure how measure the wing loading that makes the wing bent 5 degrees. The result is at $42(\mathrm{~kg})$ loading, the wing is bent but no cracks or deformations found.

From this value, these important factors are calculated for the autopilot protection systems, such as: maximum speed, stall speed, maximum bank, pitching angle.

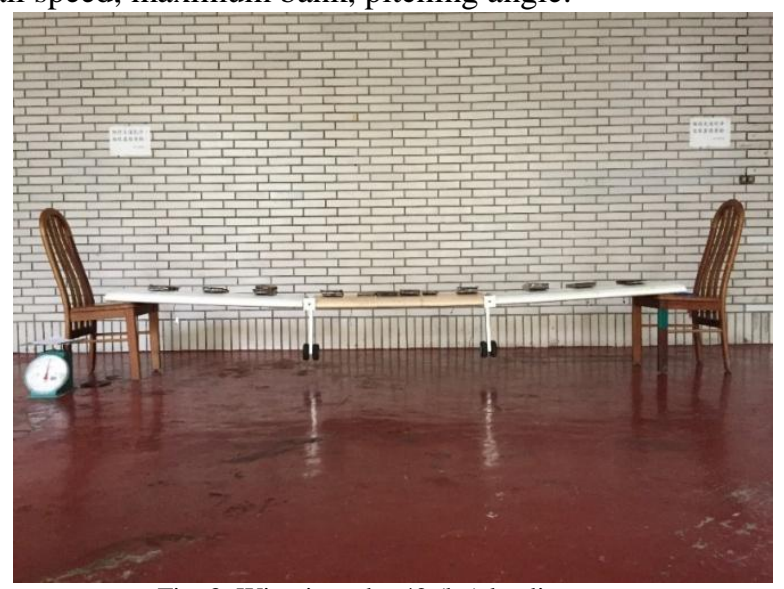

Fig. 3. Wing is under $42(\mathrm{~kg})$ loading test.

\section{Tail Design}

Depends on the specific and different mission, operating conditions, the empennage will be designed in particular shape. The conventional, T-Tail, V-Tail are suitable for the mission requirements, according to a comparison [1] shown in Table IV and Table V below:

TABLE IV: EMPENNAGE CONFIGURATION

\begin{tabular}{|c|c|c|c|c|}
\hline Factor & 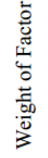 & 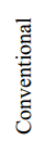 & 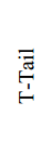 & $\begin{array}{l}\bar{\sigma} \\
\stackrel{7}{5} \\
>\end{array}$ \\
\hline Weight & 7 & 6 & 3 & 6 \\
\hline Efficiency & 5 & 5 & 6 & 4 \\
\hline Drag & 3 & 4 & 5 & 5 \\
\hline Total Score & - & 79 & 66 & 77 \\
\hline
\end{tabular}

V-tail and the conventional tail have the highest score because its structure is lighter than the T-Tail. Because the V-Tail combines the rudder and elevator into one so the control is more complicate. In conclusion, the conventional empennage is chosen because of its advantages.

A volume coefficient method is used to define the vertical 
and horizontal stabilizer area. These values are historical data which were collected from all small UAVs and aircraft [2]. The tail specifications can be calculated as below:

$$
\begin{aligned}
S_{v t} & =\frac{c_{v t} \times b \times S_{r e f \text { wing }}}{L_{v t}} \\
S_{h t} & =\frac{c_{h t} \times c \times S_{r e f \text { wing }}}{L_{h t}}
\end{aligned}
$$

TABLE V: TAIL SPECIFICATIONS

\begin{tabular}{|l|l|l|l|l|l|l|}
\hline & $\mathrm{Ct}$ & $\begin{array}{l}\mathrm{Lt} \\
(\mathrm{m})\end{array}$ & $\begin{array}{l}\text { Area } \\
(\mathrm{m} 2)\end{array}$ & AR & $\begin{array}{l}\text { Chord } \\
(\mathrm{m})\end{array}$ & $\begin{array}{l}\text { Span } \\
(\mathrm{m})\end{array}$ \\
\hline Vertical Tail & 0.055 & 1.1 & 0.23 & 1.5 & 0.04 & 0.6 \\
\hline Horizontal Tail & 0.850 & 1.1 & 0.47 & 3 & 0.04 & 1.2 \\
\hline
\end{tabular}

\section{Propulsion Design}

By using computational analysis software (ANSYS CFX5), the chart of lift (N), and power required (W) versus velocity $(\mathrm{m} / \mathrm{s})$ in each AOA are displayed in Fig.s 2-5, 2-6 and 2-7.

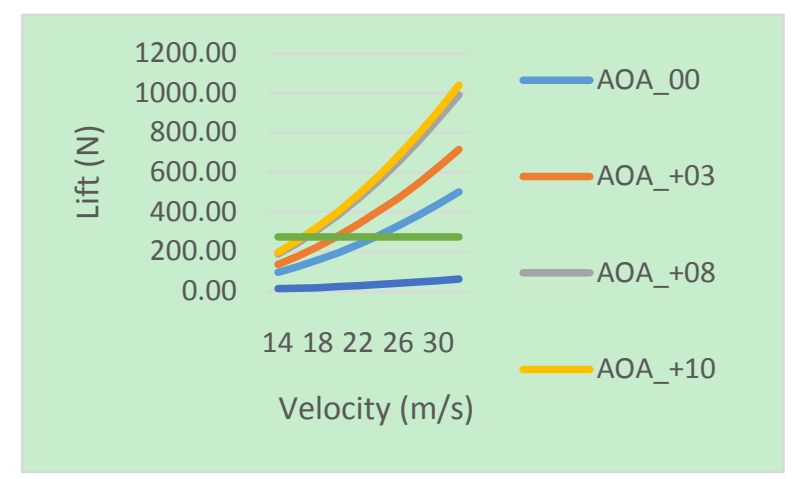

Fig. 5. Lift versus velocity.

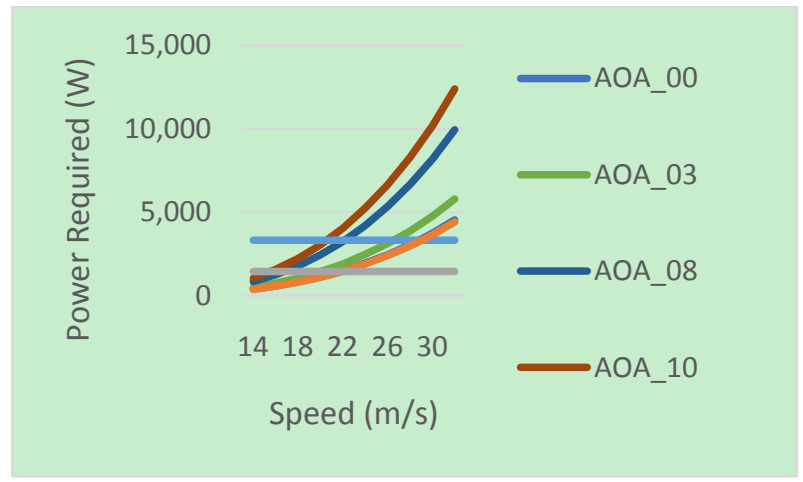

Fig. 6. Power required vs velocity.

The equation of power required in steady flight:

$$
\text { Power Required }=\frac{\text { Drag } \times \text { Velocity }}{n_{\text {motor }} \times n_{\text {propeller }}}
$$

The efficiency of propeller is about $50 \%$, motor efficiency is about $70 \%$. The power required is $1,436(\mathrm{~W})$. Besides, in order to cruise at AOA $=0$ degree with the MTOW $=28(\mathrm{~kg})$, UAV must fly at around $24(\mathrm{~m} / \mathrm{s})$, which power required is $1,938(\mathrm{~W})$. For safety, this power is achieved at $80 \%$ of motors' maximum power, the motor power is determined:

$$
\text { Motor Power }=\frac{1,938}{0.8}=2,422 \mathrm{~W}
$$

The total capability of battery can fly for about 10 minutes with two set of 10 cells battery, $42(\mathrm{~V})-5,200(\mathrm{mAh})$. The chosen motors (based on CFD analysis data) are Turnigy Glow $160-245 \mathrm{KV}$, propeller by DFDL $18 \times 10-2$ blades, battery as Power Desire 10 Cells (6S serially connect to $4 \mathrm{~S}$ ).

The difference in motors' speed creates a rolling and yawing moment, which hugely affects the performance and maneuver of the UAV. According to [4], [5], a PID controller are developed to maintain the same rotating speed on both motors.

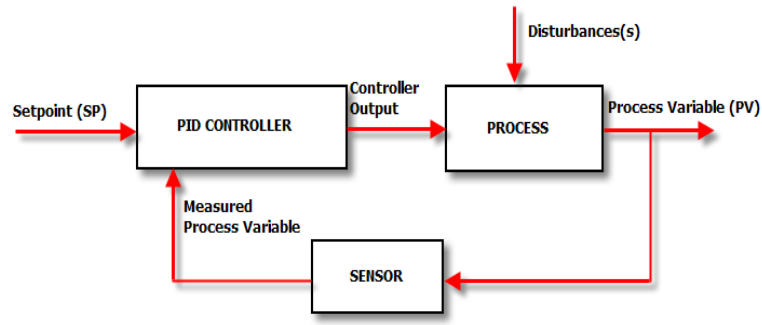

Fig. 4. A brief algorithm of speed controller.

\section{CFD ANALYSIS}

\section{A. XLFR5}

Input the proposed UAV configuration into the software for simulation. Because XLFR5 is just a simple software so that the fuselage is not defined in the software to avoid the errors at some critical area in the drawings.

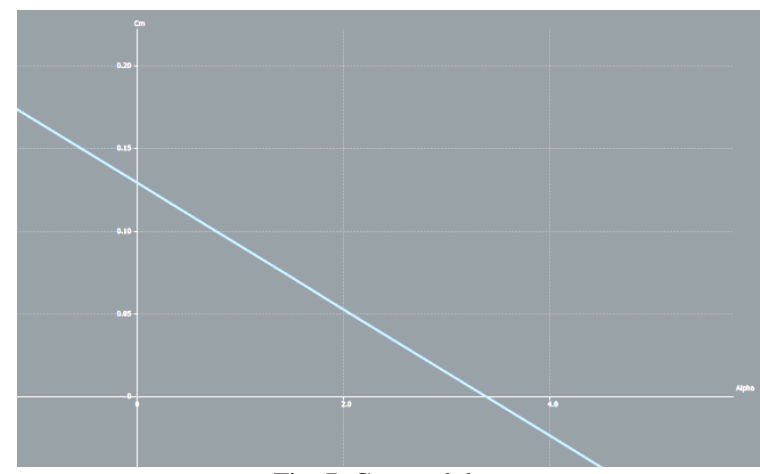

Fig. 7. Cm vs alpha.

The slope of the blue line is negative so the airplane is stable and the alpha value that makes $\mathrm{Cm}$ equal to 0 is greater than zero. Another important factor is the angle of attack which has the maximum $\mathrm{L} / \mathrm{D}$ ratio for cruising. In this simulation, maximum $\mathrm{L} / \mathrm{D}$ is at $\mathrm{AOA}=3$ (degrees).

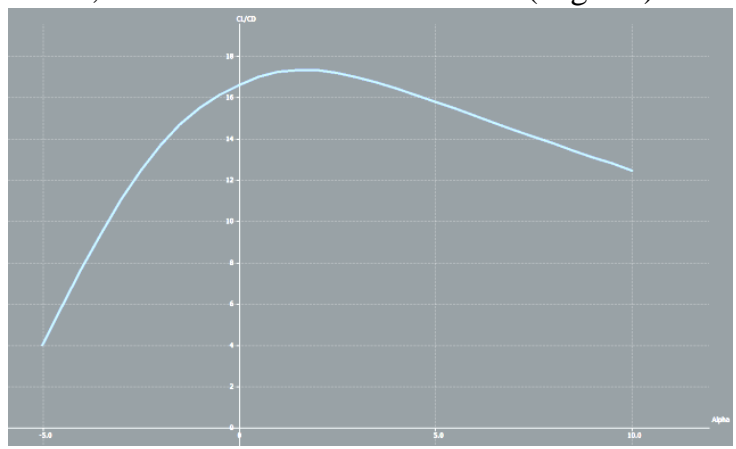

Fig. 8. Lift to Drag ratio (L/D) vs. Angle of Attack.

The dynamic stability analysis leans on roots of all the flying modes to verify the UAV performance. Both long and short modes are stable because the roots have the negative real part. And the time for UAV to return to the stable state is really fast. 


\section{B. ANSYS - CFX 5}

From now, the CFX5 software is used for a precise aerodynamic analysis. There are five cases of AOA by running (-6, 0, 3, 8, 10 degrees), each case consists of 10 cruise speed values ( 14 to $32 \mathrm{~m} / \mathrm{s}$ with $2 \mathrm{~m} / \mathrm{s}$ step). Totally, the simulation is run 50 times. Two changed parameters are the amplitude of velocity and UAV's AOA. The direction of inlet velocity is always normal to the inlet surface.

Prediction of the CFX5 simulation result: Because the fuselage is defined this time, the drag will increase, so the $\mathrm{L} / \mathrm{D}$ ratio will decrease. Besides, the lift distribution in the center part of the wing will reduce because of the affection from the fuselage. After each case is done, the result is compared with the data from XLFR5.

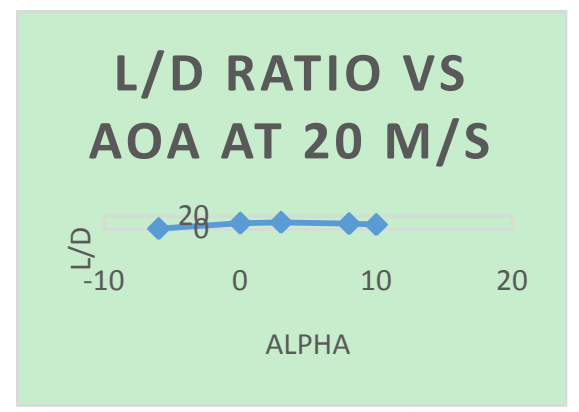

Fig. 9. L/D Ratio vs Angle of attack.

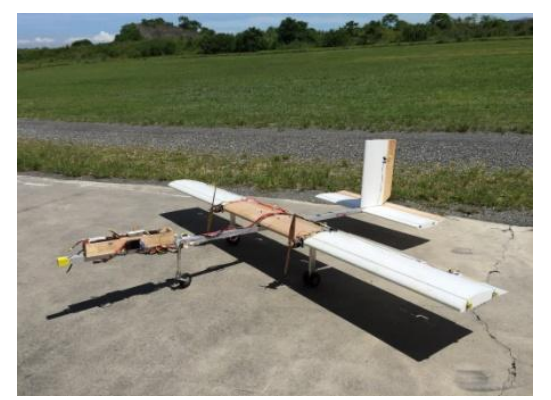

Fig. 10. Full-scale prototype is fully equipped and assembled.

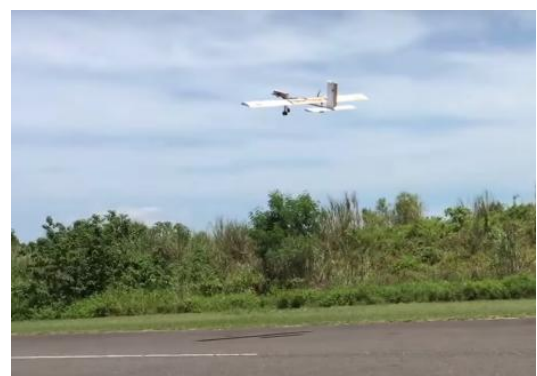

Fig. 11. The UAV takes off and flies stably.

From the simulation results, the AOA that UAV flies with highest efficiency (maximum L/D) is same as the angle calculated from XLFR5 software. The result is reliable. Finally, there are enough reliable information to manufacture the full-scale prototype.

\section{CONCLUSIONS}

The UAV has good aerodynamic performance and easily maneuvered. Besides, UAV also has good static and dynamic stability even flying in bad weather condition.

The analysis result from mid-end and high-end computational analysis software (XLFR5 and CFX5) are precise. By using these software, not only the time, cost for design phase have been shorten down but also the design quality is increased.

Moreover, the wing structure made from styrofoam, epoxy glue, fiber glass and carbon tubes is stiff enough to handle a $(17.5 \mathrm{~kg})$ lift without bending or cracking. The new wing manufacturing method outstands the traditional method in time-consumption, cost, simplicity but the weight $(30 \%$ heavier). So it is worth using a new method to make the wing for a rocket booster. More flight tests will be done to confirm the performance of the UAV.

\section{REFERENCES}

[1] M. A. H. Banna, M. R. Afsar, Z. M. S. Ali, and M. A. Salam, "Design, analysis \&amp; optimization of a small unmanned aircraft," in Proc. IEEE Aerospace Conference, 2015, pp. 1-18.

[2] C. E. Lin, Y. H. Lai, Y. C. Huang, C. C. Li, and C. C. Nien, "System design approach for experimental UAV," Journal of Aeronautics, Astronautics and Aviation, Series A, vol. 45, no. 1, March 2013, pp. 25-36.

[3] D. Kirk, "Experimental And numerical investigations of a high performance co-flow jet airfoil," Master, Science, University of Miami, United States of America, 2009.

[4] W. M. Elsrogy, M. A. Fkirin, and M. A. M. Hassan, "Speed control of DC motor using PID controller based on artificial intelligence techniques," in Proc. International Conference on,Control, Decision and Information Technologies, 2013, pp. 196-201.

[5] U. Neethu and V. R. Jisha, "Speed control of Brushless DC Motor: A comparative study," in Proc. IEEE International Conference on Power Electronics, Drives and Energy Systems (PEDES), 2012, pp. 1-5.

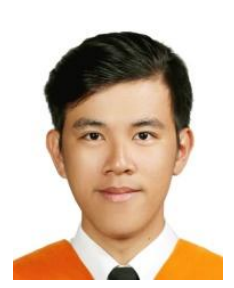

Minh Hoang Do was born in Ho Chi Minh City, Vietnam. He received the bachelor of aerospace engineering from the Department of Aeronautics and Astronautics, Ho Chi Minh University of Technology, Vietnam and he received his master of aerospace engineering from the Department of Aeronautics and Astronautics (DAA), National Cheng Kung University, Taiwan. He has been being a PhD student of DAA, National Cheng Kung University from 2016. $\mathrm{He}$ is under the advising of Professor Chin E. Lin. His research interests are vertical take off and landing aerial vehicle, UAV design, UAV flight dynamics, digital control system, embedded system, electronics and avionics system.

Chin E. Lin was born in Chang Hua, Taiwan. He received BSEE and MSEE from the Department of Electrical Engineering, National Cheng Kung University, Tainan, Taiwan. He received his doctor of engineering from the Department of Electrical Engineering, Lamar University, Beaumont, Texas, USA. Dr. Lin was a professor in the Department of Aeronautics and Astronautics, National Cheng Kung University until February 2018. His research interests are UAV flight control, air traffic control, control system applications, avionics system, wireless data surveillance system, magnetic suspension system, and sustainable energy system. 